This item was submitted to Loughborough's Research Repository by the author.

Items in Figshare are protected by copyright, with all rights reserved, unless otherwise indicated.

\title{
Operationalising “Double-Loop” learning in service organisations: A systems approach for creating knowledge
}

\section{PLEASE CITE THE PUBLISHED VERSION}

http://dx.doi.org/10.1007/s11213-016-9397-0

\section{PUBLISHER}

(C) Springer

\section{VERSION}

AM (Accepted Manuscript)

\section{PUBLISHER STATEMENT}

This work is made available according to the conditions of the Creative Commons Attribution-NonCommercialNoDerivatives 4.0 International (CC BY-NC-ND 4.0) licence. Full details of this licence are available at: https://creativecommons.org/licenses/by-nc-nd/4.0/

\section{LICENCE}

CC BY-NC-ND 4.0

\section{REPOSITORY RECORD}

Jaaron, Ayham A.M., and C.J. Backhouse. 2019. "Operationalising "double-loop" Learning in Service Organisations: A Systems Approach for Creating Knowledge”. figshare. https://hdl.handle.net/2134/23030. 


\title{
Operationalising “Double-Loop” Learning in Service Organisations: A Systems Approach for Creating Knowledge
}

\author{
Ayham A.M. Jaaron ${ }^{1}$ and Chris J. Backhouse ${ }^{2}$ \\ ${ }^{1}$ Industrial Engineering Department, Faculty of Engineering and Information Technology, An-Najah National \\ University, West Bank, 97200, Palestine \\ ${ }^{2}$ Wolfson School of Mechanical and Manufacturing Engineering, Loughborough University, Loughborough, \\ Leicestershire, LE11 3TU, UK
}

\begin{abstract}
Learning organisation literature has widely discussed the connections between “double-loop” learning and its significance to organisational performance such as knowledge creation, innovation, and enhanced competitive advantage, paying little attention to tools and models that can operationalise “double-loop” learning in organisations. This paper investigates the impact of applying a systems approach for service operations design, expressed as the Vanguard Method (Seddon, 2003), in order to activate “double-loop” learning in service organisations. Two case studies, adopting mixed methods technique, were conducted in the banking mortgage operations and adults' social care services in the UK, using the Dimensions of the Learning Organisation Questionnaire (DLOQ), semi-structured interviews, observations, and documents. The DLOQ analysis has shown high level of organisational learning capabilities at both research sites with an overall mean score of 4.00. The means of the DLOQ dimensions in both case studies range from 3.56 on dimension 4 (i.e. Embedded Systems) to 4.42 on dimension 7 (i.e. strategic leadership). The findings of the cross-case analysis support the link of applying the Vanguard Method with operationalising “doubleloop” learning through three main factors, namely systematic-operations improvement, organisational capacity development, and outside-in mode of work; that are all embedded into the seven dimensions of the DLOQ. The value of this paper is the introduction of a service operations design tool that can activate "double-loop" learning performance in the fast changing knowledge era. It also provides an impetus for service organisations to creatively influence employees’ competencies to effectively improve internal systems.
\end{abstract}

\section{Keywords}

"Double-loop” learning, learning organisation, the Vanguard Method, systems thinking, service operations, operations management.

\section{Introduction}

Inherently, organisations are exposed to rapid changes presented by dynamic external environment that cause knowledge to quickly become obsolete or invalid (Ursic et al., 2006; Wen, 2014). Organisations, in such case, need to generate new knowledge at a faster pace than their competitors to maintain competitive advantage (Putz et al., 2012). A prerequisite for organisational survival and growth in this new knowledge economy is the ability to build highly effective learning systems to improve existing working methods and adapt to rapid changes and threats (Hannah and Lester, 2009; Dahanayake and Gamlath, 2013). According to this perspective, a learning organisation is one that effectively engages with external environment, particularly customers, to improve existing methods and internal capabilities to 
encourage learning (Shipton et al., 2013). Argyris and Schön $(1978,1996)$ have described this type of learning as “double-loop” learning where long held assumptions about systems and policies are challenged by questioning existing processes and procedures. This is in contrast to "single-loop" learning defined as changing individuals' behaviour as a result of errors, without changing values and norms underlying behaviour. "Double-loop” learning, in this sense, is considered as a higher level learning which requires cultural changes in the organisation (Aksu and Ozdemir, 2005, Putz et al., 2012, Dahanayake and Gamlath, 2013). Much of the reasoning for a need for a "double-loop" learning organisation lies in the fact that, first, traditional organisations and their associated inflexible management systems and practices are inappropriate for the current dynamic environment; as they lack the capabilities needed to grasp unpredictable opportunities (Soltani et al, 2011). Second, “double-loop” learning organisations involve collecting feedback from the real world that confronts mental models of managers at work. This will then lead managers to think in terms of realities to identify opportunities for designing effective policies and fresh knowledge (Bagodi and Mahanty, 2013). Thus, “double-loop” learning encourages system-wide thinking and continuous evaluation (Tsai et al., 2010). Third, such organisations are able to withstand competition (Dahanayake and Gamlath, 2013) by converting "resources into competencies through knowledge development” (Curado, 2006).

However, learning organisation literature, so far, has widely discussed the connections between "double-loop" learning and its significance to organisational performance such as enhanced knowledge creation, innovation, and competitive advantage (Blackman et al., 2004; Maden, 2012; Synnott, 2013; Jaaron and Backhouse, 2014; Wen, 2014), paying little attention to the creation of tools and operational models that can operationalise "double-loop" learning in organisations. In fact, several researchers have argued that "double-loop” learning is rarely achieved due to lack of clear prescription of what really constitute "double-loop" learning (Dahanayake and Gamlath, 2013), and more importantly, due to organisational culture where employees risk getting into trouble if they confront managerial long held beliefs (Argyris and Schon, 1996; Fenwick, 1998; Ortenblad and Koris, 2014). As a result, many organisations fail to question the power structures and flawed techniques adopted (Synnott, 2013; Ortenblad and Koris, 2014), causing them to only undertake the "single-loop" learning track which leaves inefficient procedures of doing actions and their underpinning values unchanged (Blackman et al., 2004; Synnott, 2013). Hannah and Lester (2009) suggested that organizational reliance on "single-loop" learning, without internal processes adaptation, will lead organisations to loose congruence with evolving external environment, and eventually the organisation will demise. Although "double -loop” learning is vital for organisational survival and growth, Wen (2014) found out that organisational learning is not sufficient to secure organisational success by itself, and that connecting it with proper form of systems thinking is vital for operationalising “double-loop” learning. The challenge is, therefore, to explore how, and what form of, systems thinking facilitates and operationalises “double-loop" learning in organisations. Therefore, this paper initializes an effort to close the aforementioned gap by exploring an innovative system thinking approach for service operations design. This approach is developed by Vanguard Consulting in England (Seddon, 2003). The term "the Vanguard Method" will be used to describe this service operations 
design model throughout this paper. It is argued that the Vanguard Method is likely to operationalise “double-loop” learning in organisations by promoting a learning-centred culture focused on re-building current operations and policies based on continuous analysis of customer demand. This approach to service operations design is experiencing a significant take-up in the service sector, where it offers a considerable impact on improving the efficiency and competitive advantage of organisations (Jackson, 2009; Jaaron and Backhouse, 2014).

Shipton et al. (2013) have explained that learning organisation literature would benefit from more qualitative case study research that will progress our understanding on the availability of systems for successful implementation of organisational learning. In this research inquiry, the main objective of the study is to demonstrate how certain underlying principles of the service operations system, operating under the Vanguard Method principles, could enable operationalising “double-loop” learning in the organisation. For this purpose, two explanatory case studies conducted in the UK service sector departments are presented. The study is focused on post-the Vanguard Method implementation in the case study organisations, to investigate its proposed relationship with operationalising “double-loop” learning. Therefore, the research question sought to be answered in this paper is as follows.

RQ: How does the Vanguard Method of service operations design operationalise "doubleloop” learning in organisations?

The paper begins by outlining the concept of learning organisation. Then, the concepts of "single-loop" and "double-loop" learning are presented. Next, the methodology and philosophy of the Vanguard Method are outlined with a focus on its implementation principles. Thereafter, the research methodology is explained, and the case studies of two UK service organisations are presented. Finally, results are shown and conclusions discussed.

\section{The Concept of Learning Organisations}

The notion of learning organisation has been energised after the publication of the book "The Fifth Discipline” by Peter Senge (1990). He defined learning organisations as "organisations where people continually expand their capacity to create the results they truly desire, where new and expansive patterns of thinking are nurtured, where collective aspiration is set free, and where people are continually learning how to learn together" (p.3). Similarly, Watkins and Marsick (1993) defined learning organisations as places that learn continuously and improve themselves constantly. This is congruent with Garvin's (1993) definition where a learning organisation is seen as an organisation skilled at creating and transferring knowledge through continuous behavioural changes at work. To achieve this, Senge (1990) argued that building a learning organisation can be made following five dimensions, these are: 1) personal mastery of developing patience and viewing reality objectively by individuals, 2) development of mental models of how individuals see the world and how they act on it, 3) building shared vision of the future where individuals are committed to, 4) team learning where team members engage in developing a coordinated action, and 5) systems thinking of connecting the previous four components and viewing the organisation as whole. At a more subtle level, Ortenblad (2004) has provided four main pillars for building a learning 
organisation. First, organisational learning; where organisations are required to continuously improve their existing systems by allowing employees to challenge the current processes to learn on how they can be improved. Second, learning at work; where employees receive training on-the-job by other experienced organisational members. Third, learning climate; which provides an atmosphere where employees are encouraged to experiment new ways of doing things. Fourth, learning structure; that calls for building an organic organisation with a decentralised decision making authority, open channels of communication, and a team-based work. These dimensions have also been asserted by Davies and Nutley (2000) who introduced five key components for building a learning organisation in the health sector; these are: open systems thinking, individual capabilities, learning-oriented teams, continually updated mental models, and cohesive vision. A learning organisation, in this sense, emphasises that individuals are the focal point through which knowledge creation and information sharing can take place (Tsai et al., 2010). According to Kim (1993), individual learning is only a starting point as learning is embedded into teams' level and, ultimately, at organisational level (Tsai et al., 2010; Mohd-Zainal et al., 2011). It would be inappropriate to consider organisational learning only through individual members at the organisation (Maden, 2012). Lundberg (1995) explains that relying on individual members, alone, in the organisational learning process is not enough, as individual members do change and, therefore, the accumulative learning process can only be preserved by relocating individuals within teams. The author also states that teams would learn from external circumstances only through activities and systems embraced by the organisation itself, and not by particular individuals. Having this perspective, it would seem significantly important to build organisational operations that combine both individual and team learning levels to enhance organisational learning.

Contrary to traditional organisations, learning organisations solve problems systematically by acquiring knowledge from the external environment and then testing that new knowledge in practice (Garvin, 1993). Therefore, they learn from their own mistakes and past experiences of interacting with external context (Ursic et al., 2006). This perspective is also shared by Nevis et al. (1995) who define organisational learning as a process aimed at improving internal performance based on externally gained experiences. However, previous definitions of learning organisations, and majority of available literature on the topic, fail to involve the customer in the learning process of organisations (Shipton et al., 2013); where majority of experiences come from. Customer involvement in this process ensures that learning is directly linked with the strategic goals of the organisation (Cohen and Levinthal, 1990; Shipton et al., 2013). Pedler et al. (1999) have argued that placing the customer inputs as an integral part of the system can generate new innovative insights into the organisation. This is due to the fact that studying the flow of customer demands and inputs from the outside in fuels internal understanding of problems hidden in the system; this will provide innovative ideas to improve business operations and capabilities (Gutiérrez et al., 2012; Jaaron and Backhouse, 2014). 


\section{Characterising “Double-Loop” Learning}

For an organisation to truly be a learning organisation, generating new knowledge alone is not enough; there is a need for this knowledge to be adopted in the form of system operational and behavioural changes (Garvin, 1993; Dahanayake and Gamlath, 2013). This view is shared by Hannah and Lester (2009) who asserted that organisations can only learn by applying knowledge via adapting internal processes at multiple levels of the organisation. This view has particularly informed and moulded an effective type of systems learning called “double-loop" learning (Agyris, 1977). Argyris and Schon (1978) have outlined that organisational learning can take place at two levels; “single-loop” learning and “double-loop” learning. Arguably, this is the most widely accepted typology to understand the learning organisation concept (Hu et al., 2012). "Single-loop" learning is denoted by error detection and correction to improve individual performance without changing organisational norms or systems. It suggests that employees understand and correct the issue without reflecting on the system that has been used for this particular transaction (Lawler and Sillitoe, 2013). This type of learning is usually activated when there are transactional problems at work (Min-Huei Chien, 2004). However, Argyris (1977) and Argyris and Schon (1978) have explained that, in order to look behind mere transactional problems and errors and to dramatically improve systems, organisations need to shift to higher level learning, that is, “double-loop” learning. It occurs when organisational members challenge procedures and policies in use; which will result in developing new ways of working (Maden, 2012). It, therefore, explicitly engages all employees involved at work in providing valuable information by asking questions about how the problem originally initiated, and what procedural consequences caused the problem to happen, thus, generating a flux of useful knowledge through judicious application of information (Rowley, 2006). This provides ample evidence that “double-loop” learning is a catalyst for creating knowledge in organisations (Rowley, 2006; Bennet and Tomblin, 2006). Pun and Nathai-Balkisssoon (2011) confirmed this view by stating that knowledge management of transferring important information and expertise for dynamic learning and organisational improvement evolves only when the organisation adopts "double-loop" learning. "Double-loop" learning, this way, results in fundamental shift in mental models and views of managers due to availability of evidence on system ill-behaviour. Arising from this, "double-loop" learning is seen as "transformational" in nature rather than "transactional" (Lawler and Sillitoe, 2013). It encourages employees to reflect on the working system as a whole by learning from processes in general (Shipton et al., 2013). Therefore, the essence of "double-loop" learning is in applying an appropriate form of systems thinking of having a holistic view of the organisation that guarantees the interconnectedness with the external environment (Pun and Nathai-Balkisssoon, 2011; Bagodi and Mahanty, 2013). According to Wen (2014), systems thinking application is very essential for an organisation to look at the world and be successful at learning. This would implicitly emphasise the need for open channels of communication within the organisation and with customers. Such channels facilitate the flow of customer insights from outside in to enrich internal dialogue and organisational learning (Shipton et al., 2013). Given the complex nature of interactions within organisations, the managerial interest in operationalising "double-loop" learning in organisations has been found very limited as it was mentioned earlier. This is due to, first, managers long held beliefs that inhibit employees' reflection on the system (Synnott, 2013; 
Ortenblad and Koris, 2014). Second, the absence of a wider-ranging approach that goes beyond managers and leadership factors to consider the way operational systems are built. As a result, several models focused on promoting "single-loop" learning with little focus on activating higher level learning, such as “double-loop” learning, where innovation can be institutionalised (Wang and Ahmad, 2003; Pun and Nathai-Balkissoon, 2011).

\section{The Vanguard Method: Stemming From Systems Thinking}

"Double-loop" learning, being inherently complex concept, seems to perform better in a dynamic and complex environment (Bagodi and Mahanty, 2013). It involves the interaction of individual and team behaviours, governing policies, system operations and procedures, and turbulent inputs from the external world that increase complexity (Hannah and Lester, 2009). Several researchers have explained that managers of complex systems tend to manage the parts in order to control the whole (Capra, 1996; Gregory, 2007; Bolta, 2009). In other words, problems arising in such systems are divided into smaller problems, then attempting to solve each smaller problem separately to provide an overall solution. Ackoff (1981) argued that this reductionist approach of managing system parts without understanding the interaction between them is a main cause for system failure. This view is also shared by Gregory (2007) who added that reductionist approach cause silo working that limits organisational dynamic ability and necessary interaction between parts. It would be necessary, then, to avoid this reductionist view when dealing with complex systems, such as “double-loop" learning systems, as silo working would hamper successful learning about the system and its underlying processes and governing variables. This is brought out by the new work of Seddon (2003), described here as the Vanguard Method, of implementing systems thinking principles into service organisations' operations design. The Vanguard Method is, therefore, centred on three core elements: interrelationships, dynamics, and wholeness (Jaaron and Backhouse, 2014; Seddon, 2008; Jackson et al., 2008). A detailed account of the philosophy is reported in the work of Seddon (2008) and Jackson et al. (2008), this is also explained below.

The Vanguard Method is built around the concept of redesigning service operations based on customer demands and wants, and not around the functional hierarchies (Seddon, 2008; Jaaron and Backhouse, 2012). It builds upon principles from soft systems methodology developed by Peter Checkland (1981), the systems theory of Ohno (1988), and the intervention theory of Deming (1982). In order to deliver what the customer wants, the Vanguard Method supports a culture characterised by the formulation of a self-managing teams. It is necessary that team members are front-line employees from the workplace itself as they will be the ones to lead the Vanguard Method intervention into business operations (Jackson et al., 2008). For this purpose, the team is encouraged to find out the main purpose of the service system from the customer point of view (Seddon, 2008). This process involves spending a considerable amount of time to study the demand received by the service department at all points of contact over a period of time. The study of the demand will reveal the type and frequency of requests the business has to deal with, and will allow categorization of demand into two types; value demand and failure demand (Seddon and Brand, 2008). Value demand is what the service department has been established to serve and what the 
customers want which is of value to them. However, failure demand is the demand that the service department was not able to serve due to the lack of information, system, or supporting operations. This demand analysis period will allow the team to find out what matters to customer the most, and what they really want from the system. However, as soon as the purpose of the system, from a customer perspective, is defined, the interconnections between organisational parts become the focus to deliver that purpose (Jackson et al., 2008). The new designing process involves removing waste found in traditional processes through redesigning of the service operations based on what the customer wants (Jackson et al., 2008), and taking into consideration the inputs required from all internal business units to deliver the demand during the first contact of the customer. Seddon (2008) explained that the Vanguard Method, this way, becomes highly responsive to customers, and will significantly reduce the frequency of failure demand (Jaaron and Bakchouse, 2014). To help maintain these achievements, team members are encouraged to continuously analyse the demand received to increase their learning in the system, as this will be the only guarantee to increase employees' capability to handle demand uncertainty (Marshall, 2010). The Vanguard Method embraces the principle that team members training is not the focus in the preparation process for this kind of job, it is actually educating employees on "why" a failure happens and then supporting them to find ways to eliminate it from the system. Therefore, managers' role shifts from command-and-control to supporters. Managers are expected to be closer to their employees to help them when necessary. Bhat et al. (2012) provide a constructive view about the interactive leadership style and organisational learning. According to them, the capacity of an organisation to practice "double-loop" learning; to change old ways of doing things, and to produce original knowledge is strongly related to interactive leadership styles. As a result of this type of managers' role and the freedom of team members to change flawed operations, the organisation becomes organically structured (Jaaron and Backhouse, 2012).

Ilgen et al., (2005) stated that team members learning is “a cognitive precursor to adaptation”, that is necessary when faced with new demands (Chiva and Allegre, 2009). To achieve this, organisational teams working under the Vanguard Method have the ability to receive learning from their most experienced individuals by getting their help in trying to update and change old operations of working. The knowledge accumulated from improvement efforts of system operations will be used when dealing with new failure demands received (Seddon, 2008). Therefore, team members working in this system are equipped with empowerment and openness to communicate and interact (Jaaron and Backhouse, 2012). LePine (2003) found that empowerment and openness to communicate are critically important to activate employees' latent knowledge to perform better when the task environment changed. Emerging from all this, employees in the Vanguard Method become self-directed by reflecting on the system operations they have, and then learning how to make their own rules and decisions to absorb changes. Service operations, this way, become under more control as the data is in the hands of the people doing the work (Korkmaz, 2012). 


\section{The Vanguard Method in Practice}

The above philosophy of the Vanguard Method usually follows three main practical steps of "check-plan-do" for implementation in service organisations. These steps are summarised in Table 1, and further explained below.

Check: This is the first step towards building the Vanguard Method organisation. It is the stage where a special team from front-line employees, called the intervention team, is created. Their responsibility is to analyse customer demand to understand why the system is behaving in such a way that failure demand is received. Once the team understands the purpose of the system from a customer point of view, and the type of demand received, it can then start to map the flow of processes in the system. A flow chart of each operation in the workplace is developed to identify waste present in the system and potential blockages of delivering value demand (Seddon, 2008). All processes classified as waste are marked in red on the process flow chart. While processes that add value from a customer's point of view are marked in green.

Table 1 Three stages for implementing the Vanguard Method (Jackson et al., 2008)

\begin{tabular}{|c|c|c|}
\hline Stages in process & What is it? & What does it do? \\
\hline 'Check' & $\begin{array}{l}\text { An analysis of the what } \\
\text { and why of the current } \\
\text { system }\end{array}$ & $\begin{array}{l}\text { Provides an understanding of the system as it is and } \\
\text { identifies waste and the causes of waste. } \\
\text { 'Check' asks: What, in reality, is the purpose of this } \\
\text { system? What is the nature of customer demand? How } \\
\text { does the work flow? What is value work and what is } \\
\text { waste? Why does the system behave like this? }\end{array}$ \\
\hline 'Plan’ & $\begin{array}{l}\text { Exploration of potential } \\
\text { solutions to eliminate } \\
\text { waste }\end{array}$ & $\begin{array}{l}\text { Provides a framework to establish what the purpose of } \\
\text { the system should be and how the flow of work can be } \\
\text { improved to meet it. } \\
\text { 'Plan' asks: What is the purpose of the system from the } \\
\text { customer's perspective? What needs to change to } \\
\text { improve performance against purpose? What measures } \\
\text { are necessary in order to gauge improvement? }\end{array}$ \\
\hline ‘Do’ & $\begin{array}{l}\text { Implementation of } \\
\text { solutions incrementally } \\
\text { and by experiment }\end{array}$ & $\begin{array}{l}\text { Allows for the testing and gradual introduction of } \\
\text { changes whilst still considering further improvement. } \\
\text { Develop redesigns with those doing the work, } \\
\text { Experiment gradually, Continue to review changes, } \\
\text { Work with managers on their changing role. }\end{array}$ \\
\hline
\end{tabular}

Plan: it is at this stage where all possible solutions are explored to better design flow of operations against customer demand. The intervention team, based on what has been learned from previous stage, map out the new service operations. Team members at this stage are typically focused on minimizing non-value adding activities from a customer point of view. This is followed by building performance measures for the newly designed operations. This is usually how good employees are in creating a value demand and the percentage of value demand out of the total demand received (Jaaron and Backhouse, 2012). 
Do: this stage incorporates the experimentation of newly designed service operations by the intervention team. Once the new operations are tested and approved, a gradual roll-in of front-line employees doing the work is performed with careful observation of both employees' reaction to it and customers feedback. If needed, the operations are re-designed and re-tested again to make sure the customer get the best possible service. This is the slowest stage among the three stages as the aim is to "do it right rather than do it quick" (Jackson et al., 2008).

In order to help managers change their mental models about their old system of working, the process of building the Vanguard Method organisation starts with the check stage. This stage usually shows managers the failing of their system, and provides an evidence for the need to change their views and the way they think about their employees (Jaaron and Backhouse, 2012). Jackson et al. (2008) argued that the Vanguard Method is a continuous improvement system as it seeks to constantly identify new demands coming into the service system. Thus, new operations are designed to ensure dealing with new demands as value demands (Seddon, 2008).

\section{Research Methodology}

\section{Research Design}

Due to the need to reveal the underlying insights of the relationships identified within reallife operational context, and to uncover the contextual factors which potentially activate “double-loop” learning in organisations applying the Vanguard Method, an explanatory case study research framework adopting mixed methods technique (Tashakkori and Teddlie, 1998; Yin, 2009) was used. Meredith (1998) argued that case studies are more rigorous and preferred over the traditional rationalist methods used in operations management such as optimization techniques. He commented that case studies can be conducted in a natural setting and in a relevant context, using all possible data collection methods, which can reflect true facts. Therefore, case studies are ideal for using mixed methods research at which both qualitative and quantitative methods can be used in the same study (Leech, 2009). Further, cross-case analysis was used to analyse the data. Cross-case analysis enables the comparison of similarities and differences in the activities, processes, and systems that are the units of analysis in case studies (Khan and VanWynsberghe, 2008). Yin (2009) explained that carrying out, at least, two case studies can have stronger analytical generalisation from findings. He added that the use of two case studies will produce more valid findings to answer research questions. Therefore, two case studies were chosen for this research inquiry.

\section{Case Studies selection and characterisation}

This research inquiry took place in the summer of 2015, and covered two service organisations that are operating in the United Kingdom. The cases selected for this research were chosen with the help of "extreme case sampling” technique (Patton, 2002; Creswell, 2004) that displays extreme characteristics; where cases selected are extensively confirming patterns to illustrate high availability of the phenomena under investigation (Miles, 1994). Thus, the selection of the case study organisations was based on the availability of full application of the Vanguard Method in, at least, one service department where all service 
operations are carried out following the Vanguard Method principles. However, the case study companies' details, as well as those of the participants, are kept anonymous and the case studies will be denoted as 'Case A' and 'Case B' throughout this paper.

The first case study (i.e. Case A) was carried out at one of the Adult Social Care Departments in north Wales. The department is a main provider for a wide range of services for older people in three large areas of the region. Their services include providing equipment and adaptations, such as stair rails, ramps or stair lefts, to assist older people to live as independently as possible in their own home. They also provide tele-care equipment to call for assistance after a fall or an accident by installing a sensor at the older home to monitor risks. In addition, the department provides enablement services to support elderly people after a period of illness or accident to reclaim their independence, besides a number of other services such as providing self-sufficient flats with care and support provided as required, or providing care homes where older people can enjoy 24 hours service from professional staff. The department underwent a Vanguard Method intervention in early January 2015 due to the management recognition of high level of complaints from unhappy customers with the service. The intervention is an innovative collaboration between the National Health Service (NHS) of the UK and Adult Social Care Services Department administered by the council at that region. The intervention was remarkably successful due to the high level of integration achieved between the two firms. At the time of the study, the Adult Social Care Department had a total of 55 employees all working in the same service team under the Vanguard Method principles supported by many carers and nurses operating in the region. The team was formed of district nurse team leaders, enablement officers, and training managers responsible for rolling-in other employees to work under the new system. Before the implementation of the Vanguard Method the intervention team found out that almost $79 \%$ of the demand received in the system was failure demand as opposed to $37 \%$ at the time of the study.

The second case study (i.e. Case B) was carried out in Edinburgh at the Mortgage Operations Department of one of the largest banking groups in UK. The Banking Group is a leading UK based financial services group providing a wide range of banking and financial services, focused on personal and commercial customers. The Mortgage Operations Department is a leading provider of home buying financial services in the UK, funding almost a quarter of all UK mortgages. The department is operating in a number of locations in the UK and also offshore with almost 1700 employees in total. The Mortgage Operations Department started a Vanguard Method intervention in March 2014 in pursuit for service excellence in the market and to maintain competitive advantage. Majority of customer demands come from a large number of brokers at the rate of 70 percent of the total demand received, and the remaining 30 percent of demand is from direct customers in the region. A specially created multidisciplinary team from within the Mortgage Operations Department called the "service excellence team" was responsible for the redesign process, and through them other colleagues were taught about the new service operations design and how it works. Their role was to put the customer at the heart of the service operations redesign process by designing the work against customer demand. Therefore, the purpose of their service is "to service customer demand efficiently and effectively by understanding the individual needs of the customer, by 
offering the best customer experience”. At the time of this study, the total failure demand recorded in the system was only $27 \%$ as compared to $67 \%$ before having the Vanguard Method. However, the Vanguard Method intervention covered a total of 200 employees working in secured lending operations, insurance operations, commercial operations, credit card and fraud operations, and other mortgage acquisition processes within the department.

\section{Data Collection methods}

As it was mentioned earlier, the mixed methods technique (Tashakkori and Teddlie, 1998) was adopted in this research inquiry to collect data from each case study organisation. Both quantitative and qualitative data were collected sequentially from each case study organisation. The main sources of data were questionnaires, semi-structured interviews, observations, and operational performance documents, respectively. The Dimensions of the Learning Organisations Questionnaire (DLOQ), initially developed by Watkins and Marsick (1997) and further improved by Yang et al. (2004), was used in this study as the quantitative data collection method. The original DLOQ consisted of seven dimensions of learning in an organisation covering 43 items. The seven dimensions of learning were continuous learning, dialogue inquiry, team learning, embedded systems, empowerment, system connection, and leadership. However, Yang et al. (2004) have shortened the questionnaire to only contain 21 items for those seven dimensions. The shortened questionnaire was found to be a superior measurement tool than the 43 items version (Yang et al., 2004; Mohd-Zainal et al., 2011). Therefore, the 21 items DLOQ is sued in this study with 5-point Likert scale to confirm the availability of the learning organisation capability in both case studies. The questionnaire study was first undertaken to empirically identify whether the case study organisations have indeed developed learning capabilities as a result of applying the Vanguard Method, and to assess the extent to which both organisations practice the dimensions of a learning organisation. Data were collected over a period of one month via a mail questionnaire that has been sent to all employees working under the Vanguard Method principles at both research sites. The web-based questionnaire provided quick and easy data gathering and analysis (Creswell, 2004) as it was completed in a relatively short time. However, keeping the questionnaire short and sending it to the whole targeted population in the two case study organisations provided high response rate. Creswell (2004) asserted that "the larger the sample the less the potential error that the sample will be different from the population". A total of 255 employees were invited to take part in the survey in both organisations, out of which 168 responses were eventually returned; targeting a response rate of $65.8 \%$.

As a questionnaire study is unable alone to adequately explain real-life context (Yin, 2009), and given that service operations context and experience of staff are vital for providing a valid relevance of the findings, 14 semi-structured interviews were conducted in both case study organisations. All interviews were tape recorded and, then, transcribed shortly after interviews. A simple guiding protocol was also used as a backup to help in following major concepts in the conversations (Creswell, 2004) and to ensure the reliability of data (Yin, 2009). Interviewees were asked diverse set of questions to fully investigate the contextual factors enabling "double-loop" learning activation in the workplace as a result of the Vanguard Method implementation. For example, questions asked included: 'do you think 
people at work are allowed to help each other learn?', 'can you explain if people are allowed to question the current system operations?', 'are you allowed to try to change the way the service is delivered?', 'do you think your organisation has become a learning organisation that continuously improve systems based on feedback from customers?', 'what mechanisms are in place to create learning in the operational system?'. To supplement the data collected through interviews, observations and documents were collected. They can be used in addition to interviews to describe reality (Creswell, 2004). In fact, they helped in capturing things that were not mentioned during interviews and also helped in confirming things that were discussed with interviewees. The data sources used in the two case studies are shown in Table 2.

Table 2. Sources of case studies data.

\begin{tabular}{|c|c|c|c|c|c|}
\hline $\begin{array}{l}\text { Research } \\
\text { Site }\end{array}$ & $\begin{array}{l}\text { No. of } \\
\text { Interviews }\end{array}$ & Interviewees' roles & DLOQ & Observations & Documents \\
\hline Case A & 6 & $\begin{array}{ll}\text { - } & \text { Enablement officer } \\
\text { - } & \text { District nurse team } \\
& \text { leader } \\
\text { - } & \text { Senior physiotherapist } \\
& \text { team leader } \\
\text { - } & \text { Training manager } \\
\text { - } & \text { Project consultant } \\
\text { - } & \text { Project manager }\end{array}$ & $\begin{array}{l}\text { Circulated } \\
\text { among } 55 \\
\text { employees } \\
\text { working } \\
\text { under the } \\
\text { Vanguard } \\
\text { Method } \\
\text { principles }\end{array}$ & $\begin{array}{l}\text { All aspects of } \\
\text { operations and } \\
\text { demand } \\
\text { handling }\end{array}$ & $\begin{array}{ll}- & \text { Newsletters } \\
- & \text { Council } \\
& \text { Magazines }\end{array}$ \\
\hline Case B & 8 & $\begin{array}{ll}\text { - } & \text { Senior operations } \\
\text { manager }\end{array}$ & $\begin{array}{l}\text { Circulated } \\
\text { among } \\
200 \\
\text { employees } \\
\text { working } \\
\text { under the } \\
\text { Vanguard } \\
\text { Method } \\
\text { principles }\end{array}$ & $\begin{array}{l}\text { All aspects of } \\
\text { operations and } \\
\text { demand } \\
\text { handling }\end{array}$ & 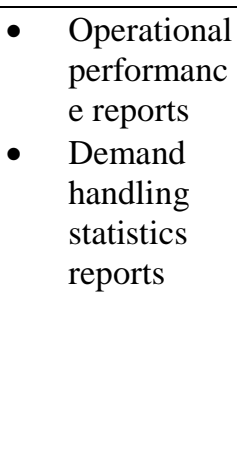 \\
\hline
\end{tabular}

\section{Data Analysis and Results}

As soon as data were collected from each case study organisation, the cross-case analysis process started. To expand the understanding of similarities and differences across cases, the results from the quantitative analysis were directly compared with results from the qualitative analysis from both case studies. First, data collected through the DLOQ from both sites were prepared for statistical analysis by scoring the data. This has given a numeric value to each response of the questions available (Creswell 2004). After scoring the data, the responses collected from the DLOQ were analysed using the SPSS (Statistical Package for the Social Sciences) software (Version 22.0). The analysis provided an examination of the availability of the learning organisation attribute. Out of the respondents, $61.31 \%$ were front-line employees dealing with customer demands as they arrive to the workplace following the Vanguard Method principles, 25.60\% were intervention team members who are also working under the Vanguard Method principles but heavily involved in applying the Vanguard Method in other areas of their working place, and the remaining respondents were a mixture 
of middle managers and team leaders of front-line employees. Details of the DLOQ respondents are shown in Table 3.

Table 3. Profile of the DLOQ Questionnaire Respondents

\begin{tabular}{|l|l|l|}
\hline Role & $\begin{array}{l}\text { No. of } \\
\text { respondents }\end{array}$ & Percentage \\
\hline Middle manager & 3 & $1.78 \%$ \\
\hline Team leader & 19 & $11.31 \%$ \\
\hline Intervention team member & 43 & $25.60 \%$ \\
\hline Front-line employee & 103 & $61.31 \%$ \\
\hline Total & 168 & $100 \%$ \\
\hline
\end{tabular}

In order to measure internal consistency and reliability for each of the seven learning organisation dimensions in the questionnaire, Cronbach's alpha was calculated for each of the seven dimensions. Cronbach's alpha results could range from 0 where no internal reliability is detected to 1.0 where perfect reliability is achieved (Cronbach, 1951), and scores above 0.70 are normally accepted as they represent good internal consistency and reliability (Vogt, 1999). However, the results of the Cronbach's alpha for the DLOQ questionnaire are shown in Table 4. The values indicate that all items are internally consistent and reliable as the Cronbach's alpha is ranging from 0.73 to 0.90 .

Table 4. Internal consistency and reliability

\begin{tabular}{|l|c|}
\hline \multicolumn{1}{|c|}{ Dimensions of the DLOQ } & Cronbach's alpha \\
\hline Continuous learning & 0.79 \\
\hline Dialogue and inquiry & 0.90 \\
\hline Team learning and collaboration & 0.81 \\
\hline Embedded systems & 0.82 \\
\hline Empowerment & 0.90 \\
\hline Systems connections & 0.77 \\
\hline Strategic leadership & 0.87 \\
\hline Overall Cronbach's alpha & 0.73 \\
\hline
\end{tabular}

Descriptive statistics from the SPSS software were calculated to find the mean and standard deviation for each item in the questionnaire, an overall mean for each dimension of the learning organisation, and a final overall mean for participants were also achieved. The means of the 21 questions range from 3.03 to 4.53, and the means of the seven dimensions of the learning organisation range from 3.56 on dimension 4 (i.e. Embedded Systems) to 4.42 on dimension 7 (i.e. strategic leadership). Table 5 provides complete descriptive statistics for the seven dimensions of the DLOQ. 
Table 5 Mean and Standard Deviation for the dimensions of the DLOQ.

\begin{tabular}{|c|c|c|c|}
\hline Dimensions of the DLOQ & $\mathbf{N}$ & Mean & $\begin{array}{l}\text { Standard } \\
\text { Deviation }\end{array}$ \\
\hline Dimension 1. Continuous learning & & 3.88 & 1.20 \\
\hline Q1. In my organisation, people help each other learn. & 168 & 4.24 & 1.49 \\
\hline Q2. In my organisation, people are given time to support learning. & 168 & 3.99 & 1.60 \\
\hline Q3. In my organisation, people are rewarded for learning. & 168 & 3.41 & 1.60 \\
\hline Dimension 2. Dialogue and inquiry & & 4.11 & 1.31 \\
\hline Q4. In my organisation, people give open and honest feedback to each other & 168 & 4.34 & 1.59 \\
\hline Q5. In my organisation, whenever people state their views, they also ask what others think. & 168 & 4.13 & 1.57 \\
\hline Q6. In my organisation, people spend time building trust with each other. & 168 & 3.86 & 1.50 \\
\hline Dimension 3. Team learning and collaboration & & 4.04 & 1.20 \\
\hline Q7. In my organisation, teams have the freedom to adapt their goals as needed. & 168 & 4.07 & 1.60 \\
\hline Q8. In my organisation, teams revise their thinking as a result of group discussions or information collected. & 168 & 4.39 & 1.54 \\
\hline Q9. In my organisation, teams are confident that the organisation will act as their recommendations. & 168 & 3.67 & 1.49 \\
\hline Dimension 4. Embedded systems & & 3.56 & 1.18 \\
\hline Q10. My organisation creates systems to measure gaps between current and expected performance. & 168 & 3.03 & 1.45 \\
\hline Q11. My organisation makes its lessons available to all employees. & 168 & 4.14 & 1.60 \\
\hline Q12. My organisation measures the results of the time and resources spent on training. & 168 & 3.53 & 1.45 \\
\hline Dimension 5. Empowerment & & 4.25 & 1.10 \\
\hline Q13. My organisation recognizes people for taking initiatives. & 168 & 4.19 & 1.57 \\
\hline Q14. My organisation gives people control over the resources they need to accomplish their work. & 168 & 4.53 & 1.48 \\
\hline Q15. My organisation supports employees who take calculated risks. & 168 & 4.03 & 1.43 \\
\hline Dimension 6. Systems connections & & 3.79 & 1.12 \\
\hline Q16. My organisation encourages people to think from a global perspective. & 168 & 3.15 & 1.60 \\
\hline Q17. My organisation works together with the outside community to meet mutual needs. & 168 & 4.27 & 1.53 \\
\hline $\begin{array}{l}\text { Q18. My organisation encourages people to get answers from across the organisation when solving } \\
\text { problems. }\end{array}$ & 168 & 3.96 & 1.52 \\
\hline Dimension 7. Strategic leadership & & 4.42 & 1.32 \\
\hline Q19. In my organisation, leaders mentor and coach those they lead. & 168 & 4.39 & 1.50 \\
\hline Q20. In my organisation, leaders continually look for opportunities to learn. & 168 & 4.27 & 1.58 \\
\hline Q21. In my organisation, leaders ensure that the organisation's actions are consistent with its values. & 168 & 4.61 & 1.71 \\
\hline Overall mean and standard deviation for the seven dimensions & & 4.00 & 1.21 \\
\hline
\end{tabular}

Despite the fact that the two research sites are operating in two different industrial sectors, it was believed that employees at both research sites have been following the exact service operations principles that resulted in a working place with several operational and job behavioural similarities. The results show a high level of organisational learning capabilities at both research sites with an overall mean score of 4.00. Although the seven dimensions' scores are all relatively above average, respondents perceived their organisations to be highest in "Strategic Leadership" with a score of 4.42, but lowest in "Embedded Systems" with a score of 3.56, indicating some potential areas for improvement. In addition, the second highest dimension is "Empowerment" with an overall score of 4.25, followed by the dimensions of "Dialogue and Inquiry" and "Team Learning and Collaboration" with overall scores of 4.11 and 4.04, respectively. These dimensions are where the double loop learning can be extirpated in the DLOQ with items testing the freedom of employees to interact and collect feedback to change things at work (i.e. items in Dimensions 2 and 3), and where organisational members challenge procedures and policies in use (i.e. items in Dimension 5); which will result in developing new ways of working if facilitated by the organisation (i.e. items in Dimension 7). This would suggest that the Vanguard Method of service operations design is an adequate catalyst for operationalising "double-loop" learning in organisations. Figure 1 provides a visual representation for the mean scores for the seven dimensions of the DLOQ in both research sites. 
Figure 1. Mean scores for each dimension of the DLOQ.

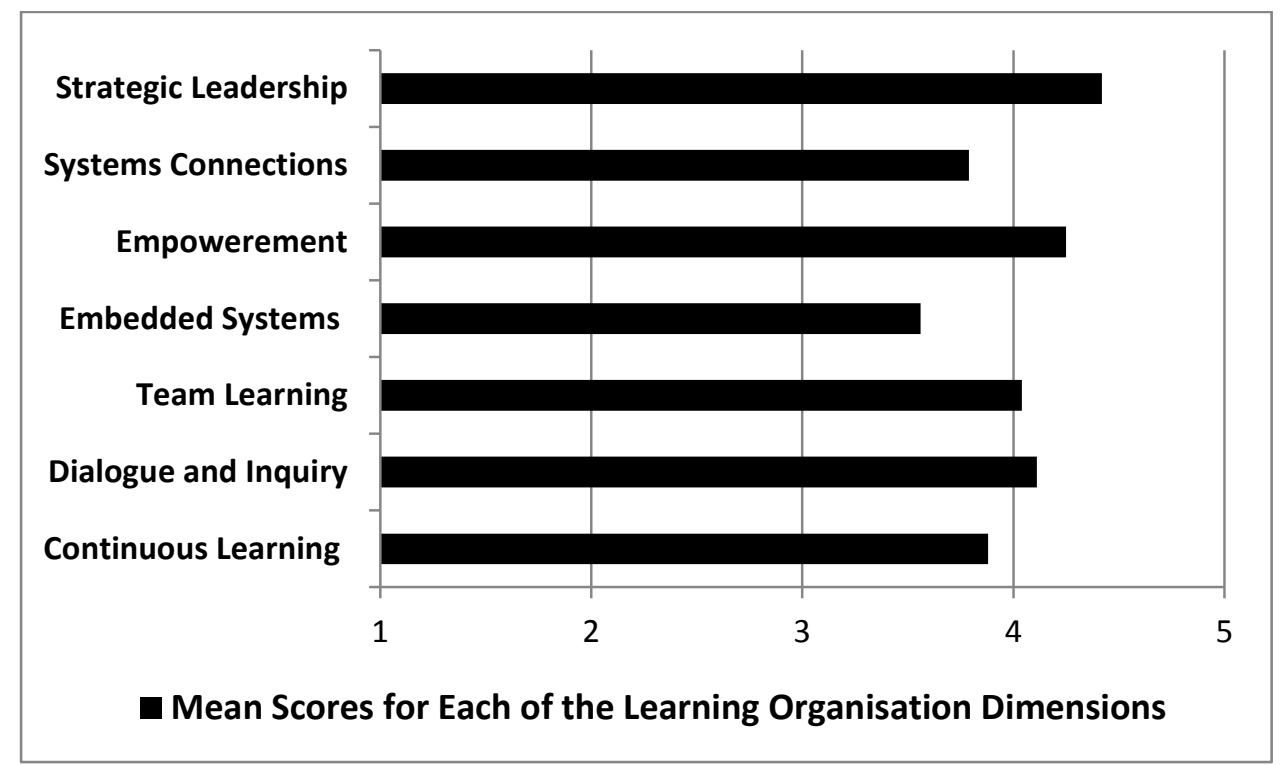

The second stage of data analysis involved using the "thematic analysis" approach (Taylor and Bogdan, 1984; Attride-Stirling, 2001) to analyse the interviews. This type of analysis maintains a high level of precision in the themes/patterns produced due to the close interaction of researcher with collected data (Easterby-Smith, Thorpe \& Lowe 2002). However, the full process of analysis followed Bryman and Bell's (2007) considerations in coding in order to achieve the analysis themes; these are illustrated in the following stages:

1) Reading through the initial set of transcripts, field notes, and documents to shed the light on general leading theoretical topics available. These theoretical topics, also called codes, were then used to list a set of words or topics that represent a general meaning of what has been said in the interviews, this is known as the coding framework of interviews analysis (Attride-Stirling 2001).

2) Reading transcripts again: This step involved reading again through the transcripts of interviews and coding the content. The interviews transcripts were then divided into meaningful fragments to facilitate dealing with the data. Every fragment or text segment was then given a word or a code that represent the meaning perceived and belongs to the pre-defined coding framework (Attride-Stirling 2001).

3) Review the codes: This step involved revising the divided transcripts to find codes with common basic themes. This was done by careful reading of the coded fragments, which enabled the identification of underlying structures and connections (AttrideStirling 2001).

4) Consider more general theoretical ideas in relation to codes and data to cluster basic themes around more central themes that were used later for interpretations.

The coding framework devised from interviews and the central themes found are shown in Table 6. The interviews analysis clearly supports the ability of the Vanguard Method to help create a "double-loop" learning organisation as a result of institutionalising three different themes. These themes are explicitly supported by the result of the DLOQ obtained earlier. The three central themes found are presented below. 
Table 6 from Codes to Central Themes

\begin{tabular}{|c|c|c|c|}
\hline Codes & Issues discussed & Basic Themes & Central Themes \\
\hline $\begin{array}{ll}\text { - } & \text { Demand } \\
\text { analysis } \\
\text { - } \\
\text { failure } \\
\text { detection } \\
\text { - Test and } \\
\text { improve }\end{array}$ & $\begin{array}{ll}\text { - } & \text { How detected problem is best } \\
\text { dealt with } \\
\text { - }\end{array}$ & $\begin{array}{l}\text { Analysing system } \\
\text { failures and } \\
\text { recording the } \\
\text { corresponding } \\
\text { lessons. } \\
\text { Creating a culture of } \\
\text { process } \\
\text { improvement }\end{array}$ & $\begin{array}{l}\text { Systematic- } \\
\text { operations } \\
\text { improvement }\end{array}$ \\
\hline $\begin{array}{ll}\text { - } & \text { Decision } \\
\text { making } \\
\text { - } & \text { Empowerment } \\
\text { - } & \text { Freedom to act } \\
\text { Leaders } \\
\text { support }\end{array}$ & $\begin{array}{ll}\text { - } & \text { Self-development through } \\
\text { experimenting new things } \\
\text { - } & \text { Managers role is different } \\
\text { - } & \text { Team working facilitates } \\
\text { operations improvement } \\
\text { - } \\
\text { Decentralisation of decision } \\
\text { making authority. }\end{array}$ & $\begin{array}{l}\text { - Changing leaders' } \\
\text { role at work } \\
\text { - Team work and } \\
\text { employees freedom }\end{array}$ & $\begin{array}{l}\text { Organisational } \\
\text { capacity } \\
\text { development }\end{array}$ \\
\hline $\begin{array}{ll}\text { - } & \text { Customer } \\
\text { - } & \text { External } \\
\text { - } & \text { Onvironment } \\
\text { Outside in }\end{array}$ & $\begin{array}{l}\text { - Focus on customer needs and } \\
\text { problems. } \\
\text { Open channels of } \\
\text { communication with external } \\
\text { stakeholders } \\
\text { - Customer demand is central to } \\
\text { learning }\end{array}$ & $\begin{array}{l}\text { - Philosophy of work } \\
\text { is all about customer } \\
\text { demands } \\
\text { Openness and } \\
\text { exposure to } \\
\text { environment }\end{array}$ & $\begin{array}{l}\text { "Outside-in" mode } \\
\text { of work }\end{array}$ \\
\hline
\end{tabular}

\section{Systematic-operations improvement}

The aim of this theme is to demonstrate the significance of the Vanguard Method in creating cultural changes in the workplace that would potentially institutionalise "double-loop" learning through continuous search for improvement opportunities by employees themselves. It also links well with the "Continuous Learning" and "Embedded Systems" dimensions of the DLOQ of encouraging people to help each other learn, and making lessons available to all employees to learn from their own initiatives. The result of interviews analysis showed a consensus among all interviewees on the importance of demand analysis in identifying operational problems and, thus, improvement opportunities in the system. Employees are now able to continuously monitor demand coming in to the workplace, and question the system operations if demand is recorded as a failure. Interviewees at 'Case A' stated that their frontline employees are now able to learn and change things by recording any failure demand received into a specially created whiteboard. These recorded failure demands are investigated by employees' direct manager on monthly basis, and then discussed collectively with employees, who will be requested by their manager to develop a new procedure or amend currently used operations to stop similar failures from being received in the future. Interviewees added that the operational changes are the responsibility of employees themselves as they are the most experienced people about the system and how it works. Similarly, interviewees at 'Case B' indicated that they are encouraged to pinpoint failure demands as soon as they received by their department. These failures are discussed at the 
team level in order to spread knowledge on why they have occurred at the first place. The team will then work collectively, through a series of meetings, to find the right system amendment to stop this failure in the future. Interviewees believe that this way of working has created a new culture where system improvement is the responsibility of everyone involved, and where employees are challenged to think about what is best for their customer.

\section{Organisational capacity development}

This theme is concerned about the role of the Vanguard Method in enhancing team work capacity, and leadership transition to a "double-loop" learning leader. This theme also links well with the DLOQ dimensions of "Dialogue and Inquiry", "Team Learning and Collaboration", “Empowerment”, and "Strategic Leadership”. The results indicate that majority of interviewees perceived that their managers and leaders role has dramatically changed. They are now more involved at the work than they were in the past. Managers are now expected to depart from performance monitoring of achieving targets to constructive support and involvement in demand analysis processes and focus on customers. Interviewees explained that this has provided employees with guidance and direction to be involved in action learning where they can try deep reforms and adaptations for serving customer better. Moreover, majority of interviewees have regarded relocating individual employees to work within teams as the most important element in the Vanguard Method through which freedom to act on the system is achieved. Teams at both research sites are now able to have freedom to test a variety of ways to solve problems creatively, through deep communication and collaborative approach. For this purpose, employees are empowered by giving them full control on what they have in hands; they rely on their innovation and intelligence to make decisions regarding customer demands and how to serve them the best. Interviewees asserted that team working, this way, has activated individual willingness and profound dialogue that are both inevitable factors for questioning system operations when faced with problems, and eventually creating improvements in the system.

\section{“Outside-in” mode of work}

This theme refers to the new philosophy of work of having the customer demand and wants in the centre of the working processes. However, the DLOQ dimension of "Systems Connections" is deemed to be closely linked with this theme as it focuses on outside stakeholders available in the external environment by encouraging people to think "outside-in" when solving problems. All Interviewees have stated that a main principle in the Vanguard Method system is designing system operations against customer demands. In their opinion, this principle will not be possible unless people are free to act on the system by understanding the surrounding world. It is only through this environmental exposure that employees can perform systematic search for elements that concern the customer the most and through which problems in the system can be identified. Furthermore, interviewees explained that understanding customer demand and the complexities available in the external environment is 
impossible to be performed using a predefined step-by-step processes provided by managers. It is because of this reason that interviewees believe that employees, in the Vanguard Method system, are encouraged to investigate business processes and systems and try to reflect on their underlying policies and procedures. Nevertheless, it was discussed that employees who encounter a customer service problem will be more committed than other employees to seeing a workable solution that provide optimal results, therefore, it is very important in the Vanguard Method that those same employees are allowed to test different ways on how a customer demand should be delivered.

\section{Discussion and conclusion}

The main aim of this research study was to investigate whether the Vanguard Method of systems thinking is significantly related to operationalising “double-loop" learning in service organisations. The study also looked at the factors and dynamics of the Vanguard Method through which "double-loop" learning organisation can be built. The paper empirically contributes to "double-loop" learning construct through the findings of the two case studies conducted that helped in answering the research question posed at the beginning of this paper. The overall results achieved from cross-case analysis have proven that the Vanguard Method is positively related to creating a "double-loop" learning organisation through the activation of three main factors, namely systematic-operations improvement, organisational capacity development, and outside-in mode of work; that are all embedded into the seven dimensions of the DLOQ. The connections between the Vanguard Method offerings and the dimensions of the DLOQ are represented in Figure 2 in a conceptual model that is supported by empirical evidence.

Figure 2. Model of “double-loop” learning.

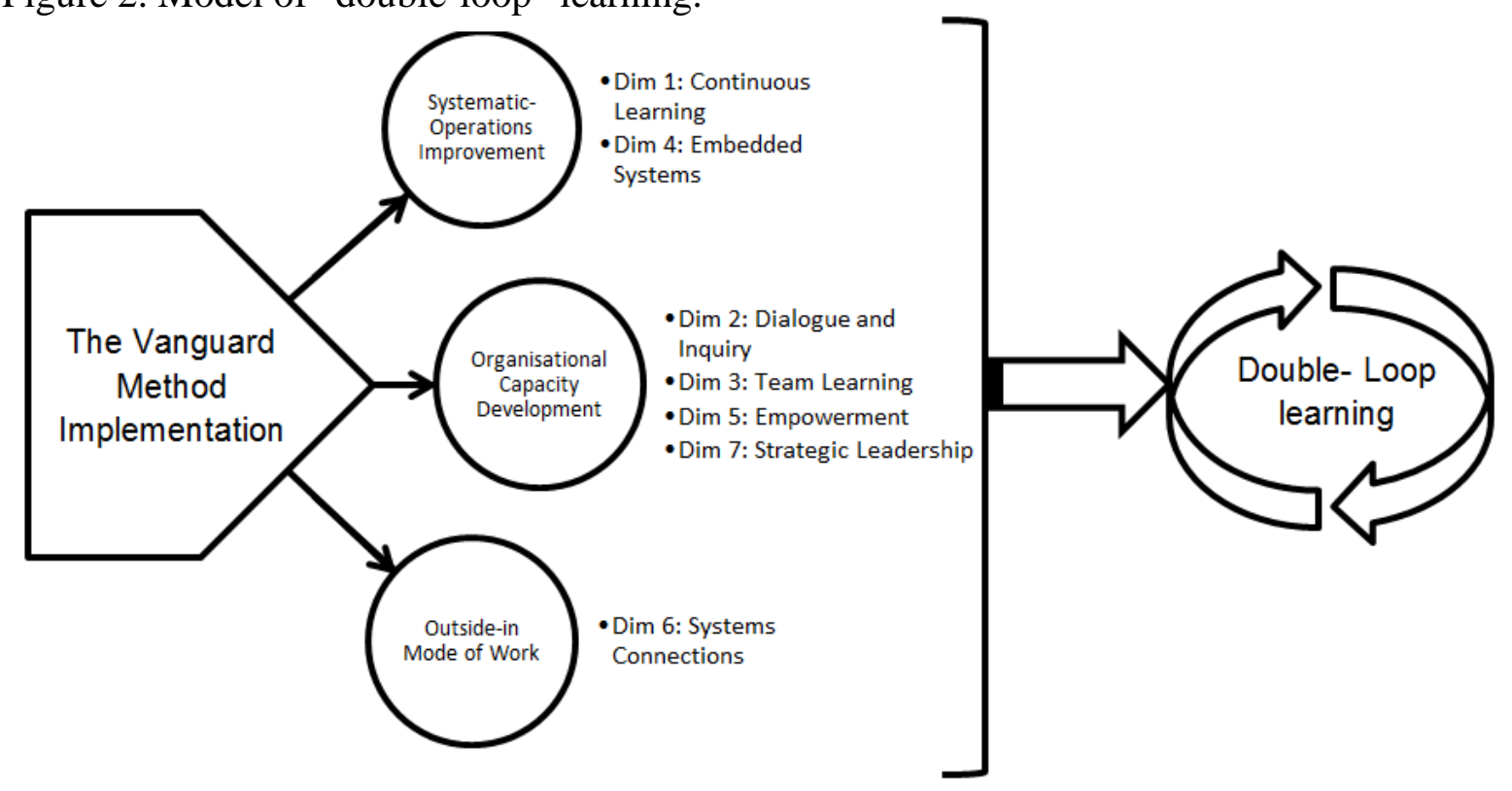

The results of interviews analysis provided important insights that are congruent with the findings of the DLOQ analysis in their support of “double-loop” learning availability as a result of applying the Vanguard Method. The interviews revealed that systematic-operations improvement is inherited in the Vanguard Method day-to-day operations. By continuously studying the customer demand, at both case studies, employees, working within teams, were able to gather knowledge about type and root cause of failure demands and errors, and thus 
creating operational changes that would prevent such failures in the future. This is similar to the findings of Cannon and Edmondson (2001) who explained that the identification of failures and mistakes in the system is the first step towards building a culture of organisational learning that relies heavily on the initiatives of its own team members. In fact, it is the engagement of employees in creating operational changes, as a result of failures, to improve the system is where the "double-loop" learning is activated (Shipton et al., 2013). The results also suggest that this principle of the Vanguard Method has the advantage of detecting majority of operational design-related failures and mistakes, which would not have been possible following traditional functional specialisation service operations design systems. For instance, Putz et al. (2012) have found that traditional organisations usually fail to recognize up to $62 \%$ of its own system failures due to lack of proper system operations design that supports guided reflections on the system failures. However, the dimensions of "Continuous Learning" and "Embedded Systems" in the DLOQ were found in the analysis to have a strong match with the theme of systematic-operations improvement. The dimension of “Continuous Leaning” revealed a relatively high level of respondents' agreement (i.e. overall score of 3.88) that their organisations are providing resources for them to learn from each other for which they are rewarded. This is in line with the interviews results explained above; that showed that employees are encouraged to search for system failures along with their colleagues working in the same team. Although respondents scored lowest on the "Embedded Systems" dimension among all seven dimensions of the DLOQ, quantitative analysis asserted that employees are highly involved in the process of learning lessons from failure cases (item 11), as compared to the remaining two items of measuring results of employees training and measuring gaps between current and expected performance of employees in this dimension (items 10 and12). A possible explanation to this result is that training is not a main concept in the Vanguard Method, since employees in this system are expected to think, analyse, judge and make decisions on the work in hands. The emphasis is in fact on explaining for employees "why" a failure has happened, as this will encourage them to improve operations to eliminate it from the system (Jaaron and Backhouse, 2014).

Moreover, the analysis of interviews at both case studies suggests that the organisational capacity development theme is another reliable enabler for "double-loop" learning. The Vanguard Method application causes the managers to shift their role from command-andcontrol role to coaching and supporting their employees. Managers at both case studies were found to be more involved at the work, as they can approach their employees to check what failures have been detected and how the teams are working to get the causes of these failures removed from the system. Managers, in this sense, take much of the responsibility to ensure that employees are able to employ and practice the principles of the Vanguard Method of detecting learning opportunities and engineering updated or new processes. This new role for managers has been explained by Wen (2014) who stated that organisational learning is impossible without active participation of managers and guide within the organisation. This is an essential contributor for organisational well-being where managers can design effective policies, to keep pace with system changes, only through "double-loop" learning. This has been supported by the dimension of "Strategic Leadership" in the DLOQ where the highest score of 4.42 was recorded by respondents. This can be attributed to the new philosophy of managers' role in the workplace; where employees are no more in need for managers to instruct them on how to do things, they now only need support and advice from their managers (Jackson et al., 2008). The new role of managers includes becoming a part of the workforce by supporting the efforts to look for opportunities to improve the system and learn, and eventually flourish. This has created amity between employees and their managers. However, the Vanguard Method requires that employees be relocated to work within teams 
(Seddon, 2008). The results showed that employees are now trusted to perform an entire demand process and if needed they can seek help from their team members to deliver a customer demand. Open channels of communications and deep dialogue between individuals are encouraged to facilitate learning. Therefore, employees are fully empowered to make necessary decisions on the cases they have. In fact, the new role of managers, explained above, fits well with empowered employees who enjoy decision making authority (Parnaby and Towill, 2012). Team members, in this environment, are able to seek more information regarding the needs of customers if a service delivery is inhibited by the current system and policies, they can then question what reasons are in place that the current system was not able to provide the requested demand. This type of probing and questioning will direct the team to go through the set of operations and policies used. In effect, this will result in modifications to the existing operations and culture. This type of team work has been regarded by Bagodi and Mahanty (2013) as the essence of “double-loop” learning, which involves gathering information from the external world to alter internal world. Nevertheless, these findings concur well with the "Dialogue and Inquiry", "Team Learning and Collaboration", and "Empowerment" dimensions of the DLOQ with an overall scores of 4.11, 4.04, and 4.25, respectively. These dimensions were highly scored in this study due to the fact that the Vanguard Method tends to build an organically structured organisation (Jaaron and Backhouse, 2014). The structure of the organisation under the Vanguard Method principles is resembled by a non-routine type of work where there is a high degree of individual authority and power at the employees' level of the organisation (Mullins 2005). The organization is viewed as the living organism that can adapt to the surrounding environment in order to survive. Employees, this way, can approach each other when needed as the personal relationships comprise an important aspect for the organizational life in such environment. Therefore, this ability to change things will promote inquiry that will challenge current actions; leading to new methods in use.

Another interesting aspect of this research is the complete reliance of the Vanguard Method on customer demands and external environment inputs to improve internal processes, activities, and systems. The results of interviews analysis have shown the importance of alignment with external customers. Taking into consideration the customer demands and wants is regarded by Shipton et al. (2013) as inevitable component for creating a learning organisation. This is also confirmed by the results of the DLOQ where the dimension of "Systems Connections" has got a relatively high level of 3.79. This congruence of the results achieved from interviews and the "systems connections" dimension can be attributed to the need for feedback from the real world (i.e. customer) to alter internal decisions and departmental relations. Thus, the mental models of employees are altered, resulting in new form of cooperation between departments involved in delivering customer service. This is the context of "double-loop" learning as described by Argyris and Schon (1978). The results also depict a culture where employees share their perspectives on different problems with other parts in the organisation. Employees in this culture think that this interaction between organisational parts is beneficial to get relevant information that could potentially help in solving problems. It is evident from the analysis that employees recognise that all incidents and events are parts of a larger whole. Apparently, employees grant significant importance for freedom to interact with other departments to insure the system improvement and adaptability. Feedback achieved from this interaction is regarded by employees as the way through which the system maintains adaptability to the environment and also to provide employees with further learning opportunities about their systems. Arguably, this gave rise to a new mode of thinking in the workplace following the systems thinking theories of interrelationships and wholeness, as systems thinking is an integral part of the Vanguard 
Method (Seddon, 2008, Jaaron and Backhouse, 2014). It is as Bagodi and Mahanty (2013) have explained that theories of systems thinking are the only way through which "doubleloop” learning can be practiced in organisations.

In practical terms, this research offers some prominent insights for practitioners and managers in service organisations. This research inquiry has set out to investigate how to operationalise "double-loop” learning in organisations as a result of applying the Vanguard Method of systems thinking. Majority of existing literature either focuses on internal variables of organisations that aspire to become a learning organisation such as individual and group learning (ignoring the role of external customers) (Shipton et al., 2013) or alternatively focuses on organisational cultures and structures of the learning organisations with no clear building methodologies for such structures (Garvin et al., 2008). This research provides straightforward step-by-step guidance on how to build an organisational service operations system that can operationalise higher levels of learning (i.e. "double-loop" learning). The work has shown that building a "double-loop" learning organisation is possible by effectively involving external stakeholders, and particularly customers, while simultaneously updating and improving internal operations. A second contribution of this work is the introduction of a tool that can build self-improving systems; by enhance employees' engagement in the process of improving organisational operations. It was evident in the results that the Vanguard Method principle of continuous demand analysis, performed by employees themselves, provides a practical method on how to influence employees' competencies. This is particularly important for managers who find themselves unable to make the most out of their employees while providing a rich working experience for them. Moreover, the focus on the external customer as the place where organisational learning emanates ensures that organisation's strategic plans are valuable. Putting the customer in the heart of the systems' improvement processes will place the customer automatically in the heart of the managerial strategic planning (Pedler et al., 1999).

\section{Study Limitations and Future Research Work}

Although this research inquiry is based on data collected from two case studies representing two different sectors, replicating this study in other industrial sectors will be necessary to determine the extent to which the findings can be generalised to other settings as well. Furthermore, paucity of previous research studies on the topic of operationalising "doubleloop” learning in organisations has limited the ability of authors to suggest grounded theory development based on the findings (Cooper and Emroy, 1995). For future research, it would be valuable to study the financial benefits of developing a “double-loop" learning organisation and how this affects organisational competitive advantage, by designing financial models that can measure financial rewards of such attribute. It would also be valuable to consider alternative external elements, other than customer demands and feedback, in the process of "double-loop" learning from external stakeholders. For example, capturing learning opportunities as a result of benchmarking practices and outside training of employees.

\section{References}

Ackoff, R.L. (1981) Creating the Corporate Future, John Wiley and Sons, New York. Aksu, A., \& Ozdemir, B. (2005). Individual learning and organization culture in leaming organizations. Managerial Auditing Joumal, 20 (4), 422-441. 
Argyris, C. (1977). Double loop learning in organizational. Harvard Business Review, 55(5), 115-125.

Argyris, C. and Scho"n, D. (1978), Organizational Learning: A Theory of Action Perspective, Addison-Wesley, Reading, MA.

Argyris, C., \& Schön, D. 1996. Organizational learning II. Reading, MA: Addison-Wesley. Attride-Stirling, J. (2001) 'Thematic networks: an analytic tool for qualitative research', Qualitative Research, Vol.1 No.3, pp.385-405.

Bagodi, V.; Mahanty, B. (2013) "Double loop learning in the Indian two-wheeler service sector", The Learning Organization, Vol. 20, No. 4/5, pp.264 - 278.

Bennet, A. and Tomblin, M.S. (2006), "A learning network framework for modern organisations: organisational learning, knowledge management and ICT support”, VINE, Vol. 36 No. 3, pp. 289-303.

Bhat, A.B., Verma, N., Rangnekar, S. and Barua, M.K. (2012) 'Leadership style and team processes as predictors of organisational learning’, Team Performance Management, Vol.18 No.7/8, pp. 347 - 369.

Blackman, D., Connelly, J., Henderson, S. 2004. Does double loop learning create reliable knowledge? The Learning Organization 11(1): 11-27.

Botla, L. (2009) 'Systems thinking: the Gandhian way', Journal of Human Values, Vol.15 No.1, pp.77-90.

Bryman, A., and E. Bell. 2007. Business Research Methods. 2nd ed. Oxford: Oxford University Press.

Capra, F. (1996) The Web of Life: a New Scientific Understanding of Living Systems, Double-day, New York.

Cannon M, Edmondson A. (2001). Confronting failure: antecedents and consequences of shared beliefs about failure in organizational work groups. J. Organ. Behav. 22:16177.

Checkland, P. (1981) Systems Thinking, Systems Practice, Wiley, Chichester.

Chiva, R. and Allegre, J. (2009) 'Organizational learning capability and job satisfaction: an empirical assessment in the ceramic tile industry, British Journal of Management, Vol. 20 No. 3, pp.323-340.

Cronbach, L.J. 1951, "Coefficient alpha and the internal structure of tests", Psychometrika, vol. 16, no. 3, pp. 297-334.

Cohen, W.M., and Levinthal, D.A. (1990), 'Absorptive Capacity: A New Perspective on Learning and Innovation,’ Administrative Science Quarterly, 35, 128-152.

Cooper, R.D. and Emroy, C.W. (1995) Business Research Methods. $5^{\text {th }}$ ed., Richard D. Irwin, Homewood, IL.

Creswell, J.W. (2004) Educational Research: Planning, Conducting, and Evaluating Quantitative and Qualitative Research, Second Edition, Ohio: Pearson Education.

Curado, C. (2006), "Organizational learning and organizational design”, The Learning Organization, Vol. 13 No. 1, pp. 25-48.

Dahanayake, N.D. and Gamlath, S. (2013), "Learning organization dimensions of the Sri Lanka Army”, The Learning Organization, Vol. 20 No. 3, pp. 195-215.

Davies HTO, and Nutley SM. (2000) "Developing learning organisations in the new NHS". British Medical Journal, Vol. 320, No. 7240, pp. 998-1001.

Deming, W.E. (1982) Out of Crisis, Cambridge University Press, Cambridge.

Easterby-Smith, M., Thorpe, R. \& Lowe, A. (eds) 2002, Management Research: An introduction, Second edn, Sage Publications, London.

Fenwick, T. (1998), "Questioning the concept of the learning organization”, in Scott, S.M., Spencer, B. and Tomas, A.M. (Eds), Learning for Life: Canadian Readings in Adult Education, Thompson, Toronto, pp. 140-152. 
Garvin, D.A. (1993), “Building a learning organization”, Harvard Business Review, Vol. 71 No. 4, pp. 78-91.

Garvin, D. A, Edmondson, A. C., \& Gino, F. (2008). Is yours a learning organization?. Harvard Business Review, March, 109-116

Gregory, A.J. (2007) 'Target setting, lean systems and viable systems: a systems perspective on control and performance measurement', Journal of the Operational Research Society, Vol. 58 No.11, pp.1503-1517.

Gutirrez Gutirrez , L.J., Bustinza, O.F. and Barrales Molina, V. (2012) 'Six sigma, absorptive capacity and organisational learning orientation', International Journal of Production Research, Vol. 50 No. 3, pp. 661-675.

Hannah, S.T. and Lester, P.B. (2009) 'A multilevel approach to building and leading learning organizations’, The Leadership Quarterly, Vol. 20 No. 1, pp. 34-48.

Hu, Q, Found, P. Williams, S. and Mason, R.. (2012). The connections between Organizational Learning and Lean Production. $23^{\text {nd }}$ International Conference of Production and Operations Management. Chicago, Il, USA, Apr. 2012.

Ilgen, D.R., Hollenbeck, J.R., Johnson, M. and Jundt, D. (2005) 'Teams in Organizations: From Input-Process-Output Models to IMOI Models’, Annual Review of Psychology, Vol. 56 No. 1, pp. 517-543.

Jaaron, A., C. Backhouse. 2014. Service organisations resilience through the application of the vanguard method of systems thinking: a case study approach. International Journal of Production Research 52(7): 2026-2041. DOI: 10.1080/00207543.2013.847291.

Jaaron, A. and Backhouse, C. (2012) 'The effects of lean thinking on service workers value productivity: a conceptual framework’, Int. J. of Quality and Innovation, Vol. 2 No.1, pp. $1-17$.

Jackson, M.C. (2009) 'Fifty years of systems thinking for management', Journal of the Operational Research Society, Vol. 60 No.1, pp. S24-S32.

Jackson, M.C., Johnston, N. and Seddon, J. (2008) 'Evaluating systems thinking in housing', Journal of the Operational Research Society, Vol. 59 No. 2, pp. 186-197.

Khan, Samia \& VanWynsberghe, Robert (2008). Cultivating the Under-Mined: Cross-Case Analysis as Knowledge Mobilization [54 paragraphs]. Forum Qualitative Sozialforschung / Forum: Qualitative Social Research, 9(1), Art. 34, http://nbnresolving.de/urn:nbn:de:0114-fqs0801348.

Kim DH (1993) "The link between individual and organisational learning. Sloan Management Review. 35(1): 37-50.

Korkmaz, O. (2012) 'Differences in employees' perception of employee empowerment practices', European Journal of Social Sciences, Vol. 34 No. 1, pp. 43-57.

Lawler, A.; Sillitoe, J. (2013). Facilitating 'organisational learning' in a 'learning institution', Journal of Higher Education Policy and Management, Vol. 35, No. 5, pp. 495-500.

Leech, N. 2009, "A typology of mixed methods research designs", Quality and Quantity, vol. 43, no. 2, pp. 265-275.

LePine, J.A. (2003) 'Team adaptation and postchange performance: effects of team composition in terms of members' cognitive ability and personality', J. Appl. Psychol., Vol. 88 No. 1, pp. 27-39.

Lundberg, C. C. (1995) 'Learning in and by organizations three conceptual issues', International Journal of Organizational Analysis, Vol. 3 No. 1, pp. 10-23.

Maden, C. (2012) 'Transforming public organizations into learning organizations: A conceptual model', Public Organization Review, Vol. 12 No. 1, pp. 71-84.

Marshall, J. (2010) 'Organisational change: evaluating systems thinking in the UK housing sector- A work in progress', in K. Zokaei, J. Seddon and B. O'Donovan (Eds.), 
Systems Thinking: From Heresy to Practice, Public and Private Sector Studies, Palgrave Macmillan, Basingstoke, pp. 108-131.

Meredith, J. 1998, "Building operations management theory through case and field research", Journal of Operations Management, vol. 16, no. 4, pp. 441-454.

Miles, M. B., and A. M. Huberman. 1994. Qualitative Data Analysis: An Expanded Sourcebook. Thousand Oaks, CA: Sage.

Min-Huei Chien, S. (2004), "A study to improve organizational performance: a view from SHRM”, Journal of American Academy of Business, Vol. 4 Nos 1/2, pp. 289-291.

Mohd-Zainal, A.; Goodyer, J.; Grigg, N., "Learning organisation in Malaysian manufacturing companies," Quality and Reliability (ICQR), 2011 IEEE International Conference on , pp.239-243, 14-17 Sept. 2011. doi: 10.1109/ICQR.2011.6031717

Mullins, L.J. 2005, Management and Organisational Behaviour, 7th edn, Financial Times Prentice Hall, Harlow, England.

Nevis, E. C., DiBella, A. J., \& Gould, J. M. (1995). Understanding organizations as learning systems. Sloan Management Review, 36(2), 73-86.

Ohno, T. (1988) Toyota Production System: Beyond large-scale production, Productivity Press, New York.

O"rtenblad, A. (2004), “The learning organization: towards an integrated model”, The Learning Organization, Vol. 11 No. 2, pp. 129-144.

Örtenblad, A., and Koris, R. (2014). Is the learning organization idea relevant to higher educational institutions? A literature review and a "multi-stakeholder contingency approach”. International Journal of Educational Management, 28(2), 173-214.

Parnaby, J.; and Towill, D.R. (2012) "Exploiting the concept of a manufacturing system part IV: The innovative action learning organisation", Journal of Manufacturing Technology Management, Vol. 23, No. 6, pp.733 - 752.

Patton, M.Q. (ed) 2002, Qualitative Research and Evaluation Methods, 3rd edn, Sage Publications, London

Pedler, M., Burgoyne, J., and Boydell, P. (1999), The Learning Company: A Strategy for Sustainable Development, Maidenhead: McGraw-Hill.

Pun, K.F.; and Nathai-Balkissoon, M. (2011),"Integrating knowledge management into organisational learning", The Learning Organization, Vol. 18, No. 3, pp. 203-223.

Putz, D., Schilling, J., Kluge, A. \& Stangenberg, C. (2012). Measuring organisational learning from errors: Development and validation of an integrated model and questionnaire. Management Learning. Prepublished June, 11, 2012. doi:10.1177/1350507612444391.

Rowley, J. (2006), “What do we need to know about wisdom?”, Management Decision, Vol. 44 No. 9, pp. 1246-57

Seddon, J. (2003), Freedom from Command and Control: A Better Way To Make The Work Work, Vanguard Education, Buckingham.

Seddon, J. (2008) Systems Thinking in the Public Sector, Triarchy Press, Axminster.

Seddon, J. and Brand, C. (2008) 'Does lean enhance public services? Debate: systems thinking and public sector performance’, Public Money \& Management, Vol. 28 No. 1, pp. 7-9.

Senge, P.M. (1990) The Fifth Discipline: The Art and Practice of Learning Organization, Century Business, London.

Shipton, H., Zhou, Q. and Mooi, E. (2013) 'Is there a global model of learning organizations? An empirical, cross-nation study', The International Journal of Human Resources Management, Vol. 24 No.12, pp. 2278-2298. 
Soltani, E.; Liao, Y.; Wang, W., "A Learning Organisation Approach to Managing Service Quality," Service Sciences (IJCSS), 2011 International Joint Conference on , pp.89,91, 25-27 May 2011. doi: 10.1109/IJCSS.2011.25

Synnott, M. 2013. Reflection and double loop learning the case of HS2. Teaching Public Administration 31(1):124-134.

Tashakkori, A. and Teddlie, C. (1998), Mixed Methodology: Combining Qualitative and Quantitative Approaches, Sage Publications, London.

Taylor, S. J., and R. Bogdan. 1984. Introduction to Qualitative Research Methods: The Search for Meaning. New York: John Wiley.

Tsai, Y.; Wu, S.W.; and Chung, H.J., "How learning organisation influences staff members' service quality," Service Systems and Service Management (ICSSSM), 2010 7th International Conference on , pp.1-6, 28-30 June 2010.

Ursic, D.; Nikl, A.; Mulej, M.; and Cester, A.S. (2006). System-organisational aspect of a learning organisation in companies. Systemic Practice and Action Research, 19(1), pp. 81-99.

Vogt, W.P. (1999). Dictionary of statistics \& methodology: A nontechnical guide for the social sciences, 2nd ed., Thousand Oak, CA: Sage Publications.

Wang, C.L. and Ahmed, P.K. (2003), “Organisational learning: a critical review”, The Learning Organization, Vol. 10 No. 1, pp. 8-17.

Watkins, K.E. and Marsick, V.J. (1993), Sculpting the Learning Organization: Lessons in the Art and Science of Systemic Change, Jossey-Bass, San Francisco, CA.

Watkins, K.E.; and Marsick, V.J. (1997) "Dimensions of the learning organization: Warwick RI: Partners for the Learning Organization.

Wen, H. (2014) "The nature, characteristics and ten strategies of learning organization", International Journal of Educational Management, Vol. 28 Iss: 3, pp.289 - 298.

Yang, B.; Watkins, K.E.; and Marsick, V.J. (2004). "The Construct of the Learning Organization: Dimensions, Measurement, and Validation," Human Resource Development Quarterly, vol. 15, pp. 31 - 55.

Yin, R. (2009) Case Study Research: Design and Methods, $4^{\text {th }}$ ed., Sage Publications, Thousand Oaks. 